\title{
How transformational leadership appears in action with adverse events? A study for Finnish nurse manager
}

\section{Liukka, Mari}

2018-09

Liukka , M , Hupli , M \& Turunen , H 2018 , ' How transformational leadership appears in action with adverse events? A study for Finnish nurse manager ' , Journal of Nursing Management , vol. 26 , no. 6 , pp. 639-646 . https://doi.org/10.1111/jonm.12592

http://hdl.handle.net/10138/308868

https://doi.org/10.1111/jonm.12592

publishedVersion

Downloaded from Helda, University of Helsinki institutional repository.

This is an electronic reprint of the original article.

This reprint may differ from the original in pagination and typographic detail.

Please cite the original version. 


\title{
How transformational leadership appears in action with adverse events? A study for Finnish nurse manager
}

\author{
Mari Liukka RN, MNSc, PhD-candidate, Manager of Quality and Safety ${ }^{1,2}$ (D) | \\ Markku Hupli MD, PhD, Chief Physician of Physical and Rehabilitation Medicine, Master of \\ Quality, Director of Rehabilitation Services ${ }^{2}$ | Hannele Turunen PhD, RN, Head of the \\ Department $^{1}$
}

\author{
${ }^{1}$ Department of Nursing Science, University of \\ Eastern Finland, Kuopio, Finland \\ ${ }^{2}$ South Karelia Social and Health Care District, \\ Lappeenranta, Finland \\ Correspondence \\ Mari Liukka, Department of Nursing Science, \\ University of Eastern Finland, Kuopio Campus, \\ Kuopio, Finland. \\ Email: mari.liukka@gmail.com \\ Funding information \\ Funding for this study was received from the \\ Finnish Nursing Association.
}

Aim: The aim of this study was to determine whether elements of transformational leadership are present in nursing managers' actions following adverse events.

Background: Transformational leadership exerts a positive influence on organisational culture and patient safety.

Method: Eleven nursing managers were interviewed individually using a semistructured format. Data were analysed using inductive content analysis.

Results: Four themes emerged relating to nursing managers' actions following adverse events: patient-centredness as a principle for common action, courage to reform operational models to prevent future adverse events, nursing staff's encouragement of open and blame-free discussion, and challenge to recognize adverse events.

Conclusion: Nursing managers must understand their responsibilities and the importance of making it clear to staff that patient-centredness should be evident in all health care actions. Nursing managers must also recognize the need to ensure that staff treat patients' interests as the top priority.

Implications for Nursing Management: If an adverse event occurs, the situation should be discussed with the nursing staff and any unique aspects of the event must be accounted for. Nursing managers must have the skill to motivate and empower staff to find new ways to work, to prevent adverse events and to promote patient safety.

KEYWORDS

adverse event, nursing management, patient safety, transformational leadership

\section{1 | INTRODUCTION}

\section{1 | Transformational leadership}

Transformational leadership in nursing has been described as a process in which leaders seek to motivate their staff, and to satisfy the staff's higher needs and ideals (Page, 2004). If implemented correctly, this allows nursing staff and leaders to support one another and reinforce each other's motivation such that their objectives, which may initially differ, gradually become fused (Page, 2004).

The most important component of transformational leadership is idealized influence or charisma (Bass, 1995). Leaders with these qualities are role models for their staff; they are charismatic visionaries with a positive view of the future who can motivate and empower nursing staff to work towards the organisation's vision while maintaining a strong focus on patient safety. Consequently, their staff can easily identify with their leaders' goals. Additionally, nursing managers (NMs) who possess these qualities can effectively increase the nursing staff's knowledge and ensure they understand which issues are most important in their work (Bass, 1995; Bass \& Steidlmeier, 1999; Marshall, 2011; McFadden, Stock, \& Gowen, 2015; Merrill, 2015). This is important because nursing managers have a challenging role to play in their units: they must strike a balance between the goals and values 
of the nursing staff, and the broader vision of the organisation (Doody \& Doody, 2012). This requires close interaction between the leader and their staff; as a result, transformational leaders are trusted, visible and often seen with new staff (Bass \& Avolio, 1997; Merrill, 2015). Hillen, Pfaff, and Hammer (2015) reported that frequency of incident reports correlated positively with the adoption of transformational leadership practices, suggesting that a visionary and interactive leadership style promotes organisational learning and better patient safety outcomes.

Transformational leaders also use inspirational motivation skills to motivate nursing staff (Doody \& Doody, 2012) and to increase understanding of shared goals through demonstrations and by providing symbols (Bass \& Avolio, 1997). These skills allow them to describe important goals to staff in simple terms (Bass, 1990). A recent study found that $67 \%$ of staff wanted managers to have a positive attitude to innovation, and $90 \%$ strongly agreed that managers must have motivational skills (Rawat, 2015). These skills are important for maximizing the ability for staff to learn from adverse events (AEs). Effective organisational learning is required to prevent adverse events and actions, and to maintain and develop a strong patient safety culture (Vaismoradi, Griffiths, Turunen, \& Jordan, 2016).

Leaders who provide intellectual stimulation encourage nursing staff to question their traditional ways of working, to think for themselves, and to question the organisation's and leaders' values, beliefs and expectations (Bass \& Avolio, 1997). Proficient nursing managers encourage and empower staff to solve problems using evidencebased practices; ways of working should always be adopted on the basis of evidence rather than tradition (Doody \& Doody, 2012). Another important aspect of intellectual stimulation is that nursing staff are encouraged to get involved with safety initiatives introduced by nursing managers and given support to do so (Vincent, 2010).

Leaders who offer individualized consideration encourage their staff to reach for higher goals, and support them in these efforts. Staff are treated equitably while recognizing that they are unique individuals, and are given personal attention (Bass, 1990; Bass \& Avolio, 1997; Doody \& Doody, 2012). Nursing managers should seek to empower their staff, for example by holding regular meetings with them. During these meetings, the staff can discuss strategies for implementing the organisation's vision and improving safe patient care, as well as discussing adverse events openly and without blame (Doody \& Doody, 2012; Turunen, Partanen, Kvist, Miettinen, \& Vehviläinen-Julkunen, 2013).

\section{2 | Patient safety and incident reporting}

Incident reporting plays an important role in preventing adverse events and is an essential component of safety management (Qin, Xie, Jiang, Zehn, \& Ding, 2015). Each incident report should be analysed, using structured methods such as root cause analysis if necessary. The analysis should be performed by a multidisciplinary team, and should begin with a process of collecting data and interviewing persons who were involved in the adverse event to get a clear picture of what happened. The goal should be to find out how and why the adverse event occurred (Agency for Healthcare Research and Quality [AHRQ] 2017; Vincent, 2010), and the results must be discussed with the staff (Hoffmann \& Rohe, 2010). During these discussions, it is important to describe the adverse event in a way that ensures all attendees reach a common understanding of what happened and why it occurred. The goal must be to create new ways of working that prevent such events from reoccurring. It is important to note that it is not helpful to set goals relating to the number of reports that are generated (Hoffmann \& Rohe, 2010). Discussion about adverse events should be blame-free, and staff should not fear punishment; focusing blame on individuals does not support development (Vrbnjak, Denieffe, O'Gorman, \& Pajnkihar, 2016). Visionary leadership styles such as transformational leadership correlate positively with both incident reporting and patient safety outcomes (Hillen et al., 2015; Wong, Cummings, \& Ducharme, 2013).

\section{3 | Transformational leadership and patient safety}

Wong et al. (2013) found that transformational leadership was associated with lower patient mortality, fewer medication errors, lower rates of pneumonia and urinary tract infections and fewer patient falls. It has been argued that these improvements in patient safety occur because transformational leaders treat errors as opportunities to improve processes, and encourage the reporting of near misses and adverse events (Merrill, 2015).

Transformational leaders seek new ways to work and focus on future needs rather than only current needs (Saeed, Almas, Anis-ulHaq, \& Niazi, 2014). They use many professional skills to this end, including empathy, listening and coaching (Marshall, 2011). They also acknowledge personal achievement (Merrill, 2015), and consider it important for team members to work together (Marshall, 2011). A hallmark of transformational leadership is that leaders focus on developing nursing staff to become leaders themselves (Bass, 1995). Staff in units whose managers use transformational leadership methods have better job satisfaction, better conflict management, and greater psychological well-being than those in units whose managers adopt transactional or dissonant leadership styles. Additionally, their units exhibit a stronger innovation culture (Cummings et al., 2010; Kim \& Yoon, 2015; Munir, Nielsen, Garde, Albertsen, \& Carneiro, 2012; Weng, Huang, Chen, \& Chang, 2015). The literature thus indicates that transformational leadership improves the quality and safety of care. However, more knowledge is needed about which aspects of transformational leadership are important in managing adverse events.

\section{4 | Aims}

The aim of this study was to determine whether elements of transformational leadership are evident in nursing managers' actions following adverse events. 


\section{2 | METHODS}

\section{1 | Sample}

The hospitals examined in this study have used a common incident reporting system known as HaiPro since 2011. The system is electronic and fully anonymized. When a report is created, it is sent to the manager who supervises the report's creator for analysis; in principle, the results of the analysis should then be discussed with the staff. The events of interest are near miss situations or injuries caused by treatment that harmed a patient. For example, both incorrect administration of medicine and falls could be defined as adverse events (National Patient Safety Foundation [NPSF], 2017). Staff in these hospitals have been educated to use incident reporting system and reporting is recommended.

Every nursing manager at one acute hospital and one primary care hospital was invited to participate in the study via email. In organisational terms, the primary care hospital and the acute hospital had common administrative elements. Together, these hospitals have 414 beds and 22 nursing managers. Eleven $(n=11,50 \%)$ nursing managers chose to participate. All were women; their average age was 50 . All of them were registered nurses with different kinds of further education and 10 years' management experience on average. The units they managed had between 18 and 85 employees. In 2014 , a total of 1,418 incidents were reported across the participants' hospitals.

\section{2 | Data collection}

Nursing managers were interviewed individually using a semistructured format. The interview protocol focused on discussing adverse events in units. The managers were asked the following questions: Do you speak openly about adverse events when they occur? What is the aim of these discussions? What factors prevent and promote open discussion? In addition, they were asked whether they had personally been involved in any patient safety incidents and how those incidents were dealt with. However, the responses to those questions are outside the scope of this paper.

The semi-structured interviews lasted between 20 and $90 \mathrm{~min}$; the average duration was $27 \mathrm{~min}$. Interviews were audio recorded and then transcribed verbatim by the researcher. The full transcripts were then carefully reviewed several times to ensure accuracy (Vaismoradi, Turunen, \& Bondas, 2013). All interviews were performed face-to-face in a hospital, in the nursing manager's own office or in the hospital's meeting rooms, during the winter of 2013-2014.

\section{3 | Data analysis}

The aim of the data analysis was to determine whether any elements of transformational leadership were visible in the managers' actions following adverse events. The data were analysed using

TABLE 1 Example of analysing

\begin{tabular}{|c|c|c|c|}
\hline Raw text & Condensed meaning unit & Subtheme & Theme \\
\hline $\begin{array}{l}\text { 'When we go through risks which are related to } \\
\text { patient care, everybody has to know how to do } \\
\text { things' }\end{array}$ & $\begin{array}{l}\text { The common understand- } \\
\text { ing of the issue }\end{array}$ & $\begin{array}{l}\text { Compliance with common } \\
\text { practices }\end{array}$ & \\
\hline 'We have to have these agreed methods' & Agreed methods & & \\
\hline $\begin{array}{l}\text { 'We should have written guidelines about those } \\
\text { agreed methods' }\end{array}$ & Written guidelines & & \\
\hline 'I see it as a very important guiding star' & $\begin{array}{l}\text { Patient safety as a guiding } \\
\text { star }\end{array}$ & & \\
\hline $\begin{array}{l}\text { 'We should have same kind of ethical conscience } \\
\text { toward patient safety as we have toward } \\
\text { hygiene' }\end{array}$ & $\begin{array}{l}\text { Ethical approach to patient } \\
\text { safety }\end{array}$ & $\begin{array}{l}\text { Action for the patient's best } \\
\text { interests }\end{array}$ & $\begin{array}{l}\text { Patient- centredness as a } \\
\text { baseline for common action }\end{array}$ \\
\hline $\begin{array}{l}\text { 'We are here for patients and all what we do } \\
\text { should promote patients' best' }\end{array}$ & $\begin{array}{l}\text { Promotion of the good of } \\
\text { patients }\end{array}$ & & \\
\hline $\begin{array}{l}\text { 'Actually I see that everything we do in our unit } \\
\text { should relate to patient' }\end{array}$ & $\begin{array}{l}\text { All actions should be } \\
\text { related to patient }\end{array}$ & & \\
\hline $\begin{array}{l}\text { 'It is everyone's responsibility to ensure that } \\
\text { patients get safe and good care, regardless of } \\
\text { their profession' }\end{array}$ & $\begin{array}{l}\text { Ensuring the safety of the } \\
\text { patient is everybody's } \\
\text { responsibility }\end{array}$ & & \\
\hline $\begin{array}{l}\text { 'Patient safety should be number one to all health } \\
\text { care professionals' }\end{array}$ & $\begin{array}{l}\text { Patient safety should be } \\
\text { number one for } \\
\text { everybody }\end{array}$ & & \\
\hline $\begin{array}{l}\text { 'We read reports together and try to get } \\
\text { understanding what has happened' }\end{array}$ & $\begin{array}{l}\text { Rereading incident reports } \\
\text { for lessons learned }\end{array}$ & $\begin{array}{l}\text { Learning from own mistakes } \\
\text { and near misses what has } \\
\text { happened }\end{array}$ & \\
\hline $\begin{array}{l}\text { 'The goal of discussion is that we learn from errors } \\
\text { and near misses' }\end{array}$ & $\begin{array}{l}\text { Learning from errors and } \\
\text { near misses }\end{array}$ & & \\
\hline
\end{tabular}


inductive content analysis. This method is used when there is a lack of previous studies on the phenomenon of interest (Vaismoradi et al., 2013). Interesting statements from the transcripts were extracted and categorized into subthemes, and the subthemes were then categorized into themes. No specialized software was used in this process. A single researcher coded all the interview responses and performed the initial analysis; the second researcher then critically reviewed the coding and analysis. The analytical process is illustrated in Table 1.

\section{4 | Ethical consideration}

Ethical approval for the study was granted by the University Committee on Research Ethics (code number 2/2011). Permission for the study was obtained from the study hospital. All participants were volunteers and were not paid for participating.

Participants were informed about the voluntary nature of the study in the email message conveying their invitation to participate. Participants who answered to the email told that they will take a part to the study indicating their consent. Before each interview, the interviewee was again informed about the voluntary nature of participation, and told that they could halt their participation whenever they wanted. They were also informed that only the researcher would know who had participated in the study. The interviewer works in the studied organisation as a consultant and does not hold a position of supervisory authority over any of the participants.

\section{FINDINGS}

Four themes emerged from the analysis: (1) patient-centredness as a principle for common action, (2) courage to reform operational models to prevent future adverse events, (3) nursing staff's encouragement of open and blame-free discussion, and (4) challenge to recognize adverse events.

It emerged that nursing managers only communicated with nurs ing staff about an adverse event if they knew that the adverse event had happened. Nursing managers emphasized the importance of an open organisational culture and having the courage to report errors. They also highlighted nursing managers' responsibility to ensure that staff always think about patient safety issues when working. The four emergent themes are briefly discussed below.

\section{1 | Patient-centredness as a principle for common action}

Nursing managers emphasized the importance of ensuring staff understand that patient-centredness should be considered in all health care actions, meaning that patients' interests should be given the top priority in any action taken by any member of staff. They also emphasized that everyone within the organisation is responsible for ensuring that patients are cared for safely. Units should have written guidelines and rules so that everyone knows how work should be done, and that all staff members should comply with these rules and guidelines. Patients must be treated equally, so all patients must receive the same standard of care while accounting for their individual needs. By definition, every patient has some kind of health problem. It is the responsibility of health care professionals to do everything in their power to avoid making patients feel worse; if an error happens, staff must review their competences and learn from their errors. Interview responses reflective of this theme include:

'Essentially, I believe that everything we do should connect to patients' care, and patient safety is part of that' (NM6)

'I see it (patient safety) as a very important guiding star'. (NM9)

'It is everyone's responsibility to ensure that patients get safe and good care, regardless of their profession.' (NM10)

\subsection{Courage to reform operational models to prevent future adverse events}

Nursing managers considered it important for nursing staff to report the occurrence of adverse events to them, and emphasized the need for a common discussion to review the causes of each event. The managers also stressed the importance of discussing adverse events so that staff understand why these errors happen. Questions that the managers considered important in these discussions include: Why did this error happen? When did things go wrong? What should we do to ensure this never happens again?

'We must find a new way to work so that an $A E$ of this kind never happens again' (NM7)

A recurring theme was that the managers felt that both managers and staff should look forwards and think of new ways to work when confronted by problems that pose risks to patient safety. Nursing staff should not feel that they cannot do anything to reduce such risks. The causes of adverse events should be discussed so that solutions can be developed collaboratively and patient safety can be improved. These points are illustrated by the comment below:

'People must have the courage to report (adverse events). We also have to talk so that we can change the way we work.' (NM6)

Discussion and reporting of adverse events could help to identify patient safety risks. The goal of these discussions should be to ensure that nursing staff can identify in advance situations where an adverse event could occur.

'The goal of these discussions is to ensure everyone knows the risks and is aware that an event happened in this 
situation, and that it could happen again in future if we don't find a solution.' (NM4)

\subsection{Nursing staff's encouragement of open and blame-free discussion}

The creation of a blame-free culture in nursing units will require more encouragement for staff to report and discuss adverse events. Adverse event reports should therefore be handled without making staff feel guilty. The incident reporting system in the studied organisation was fully anonymized; some of the participating managers felt that this increased the number of reports that were submitted.

'We don't have to find guilty parties when discussing adverse events.' (NM3)

While it is clearly undesirable for adverse events to happen, the managers emphasized the importance of creating a culture that recognizes that everyone makes mistakes. One nursing manager noted that nursing staff prefer to report other people's mistakes rather than acknowledging their own:

'I feel, of course, that it is my job to encourage nursing staff to avoid hiding and covering up their mistakes, and to bravely confront adverse events.' (NM4)

'You need a culture that is in a way both open and confidential... and for people to be more interested in that factor (patient safety). I don't know... it should be one of my duties.' (NM10)

\subsection{Challenge to recognize adverse events}

Nursing managers considered it important for nursing staff to be able to talk about anything with their nursing manager without fear of blame or punishment. If nursing staff feel fear, they will not report adverse events, so nursing managers will be unable to discuss those events. Consequently, the managers will be unable to develop their operational models to improve patient safety. These issues are reflected in the following remark made in one of the interviews:

'I don't know why they don't talk about them (adverse events) there (team meetings). Maybe it is because nursing staff don't talk about them generally - things have to be pretty bad for me to find out. It may be that they are afraid.' (NM1)

The managers had also noticed that nursing staff may blame themselves for events, feel ashamed, and worry about what their colleagues might think of them after a patient safety incident. It is also possible that some nursing staff would be willing to report their own mistakes but not those committed by some colleagues.
'Well, I think that blame is a problem - it can be hard to confess and say I screwed up' (NM5)

I think that in our unit many nurses find it difficult to own up to their own errors if they know that those errors will later be discussed as a group, or if they feel that those discussions don't lead anywhere, or if the NM is indifferent to such events.' (NM5)

\section{4 | DISCUSSION}

The results revealed that some elements of transformational leadership are important in nursing managers' actions following adverse events. The nursing managers generally agreed that patient safety should be the primary concern of all nursing staff and managers, and that patient-centredness should be at the core of all common actions. This clearly reflects the "idealized influence" aspect of transformational leadership-specifically, the inculcation of shared values (Marshall, 2011). These values must be clearly articulated to all staff so that everybody knows what they are and how they are to be understood. Nursing managers must ensure that nursing staff are committed to working in a patient-centred fashion, to promote patients' interests. Nurses who know their managers' expectations about patient safety show a stronger understanding of patient safety and report greater numbers of adverse events or near misses (Ammouri, Tailakh, Muliira, Geethakrishnan, \& Al Kindi, 2015). This study shows that nursing managers see it as their responsibility to ensure that staff keep patient safety questions in mind and encourage nursing staff to report adverse events. They understand that there is a need for courage to reform operational models to prevent adverse events, and that nursing staff must be encouraged to discuss adverse events openly and without blame. Additionally, the nursing managers recognized that if they do not show interest in adverse events and their causes, nursing staff will not report events and so the underlying risks to patient safety will not be addressed.

The nursing managers also showed 'idealized influence' in their recognition of the need for written guidelines and rules to ensure that all staff understand how work is to be done and that patients' interests should be the main priority-the guiding star. Transformational leaders are role models for their staff (Marshall, 2011), so nursing managers should lead by example, by actively taking up patient safety questions. Such actions allow nursing managers to demonstrate the unit's goals and values to staff.

The participating nursing managers agreed that all adverse events should be reported. The results suggested that the managers saw themselves as motivators who encourage nursing staff to report adverse events, and they acknowledged the importance of discussing adverse events to ensure that nursing staff understand why errors happen. They also described holding discussions with staff and giving feedback or asking for their points of view. Previous research has shown that in units where feedback about adverse 
events is routinely given, staff have positive views on patient safety and report adverse events more frequently (Ammouri et al., 2015). This can be regarded as an example of 'inspirational motivation' in terms of transformational leadership, in that the managers are encouraging staff to reach their goals (Doody \& Doody, 2012). In addition to their perceived role as motivators, the managers clearly recognized that they are responsible for ensuring that patient safety issues are kept in mind and that patient-centredness is the key priority in their units.

The nursing managers noted that health care professionals should not feel that they can do nothing to reduce patient safety risks. The goal of discussing adverse events is to ensure that everybody is aware of hazards that can jeopardize patient safety, and to help establish a culture in which staff feel they have the power to change the ways they work to prevent such events in future. Therefore, discussions about adverse events should provide "intellectual stimulation". If an adverse event occurs, nursing staff must find a new way to work to ensure it is not repeated.

The nursing managers recognized that staff are unlikely to report incidents if they fear punishment or blame. One way to create a blamefree culture is to increase the involvement of staff in decision mak ing and policy development (Merrill, 2015). It is necessary for nurse managers to discuss adverse events in team meetings and to make sure that staff understand that errors happen to everyone. This can be seen as an example of individualized consideration if the discussions are held regularly and with a positive attitude (Doody \& Doody, 2012; Heuston \& Wolf, 2011). These kinds of team meetings are a good way to empower staff to create safer patient care and an open patient safety culture, which is a major part of the work of a transformational leader (Doody \& Doody, 2012). Team meetings must be held regularly, but participation in discussions about patient safety incidents should be voluntary. Nursing staff must be treated as individuals, and managers should not pressure people to offer opinions if they are not comfortable doing so. The nursing manager must therefore have the skill to identify the individual needs of staff members and their readiness to discuss patient safety incidents so that a safe environment can be created.

Overall, these results show that some elements of transformational leadership are visible in nursing managers' handling of adverse events. Transformational leadership is important in this context because it improves patient safety and promotes innovative behaviour by nursing staff (Weng et al., 2015). By encouraging staff to talk about adverse events, nursing managers can encourage the development of new ways of working or new tools that improve patient safety. However, it is interesting that when discussing these issues, the nursing managers frequently said "I/we should..." instead of "I/we have..." or "I/we do..." This may indicate that they are aware of the correct ways to lead staff in patient safety questions but are not actually doing it. This interpretation is supported by one participant's comment about "how things have to be pretty bad for staff to talk about an incident with their nursing manager". Alternatively, it could be indicative of careless attitudes towards patient safety among the staff.

\section{5 | TRUSTFULNESS, LIMITATIONS AND SUGGESTIONS FOR FUTURE RESEARCH}

This study had only 11 participants. However, the gathered data were rich, and various responses and themes occurred repeatedly, indicating that increasing the number of participants might not provide significantly more information; in other words, it appears that saturation was achieved. Importantly, there were many commonalities in the managers' descriptions of their actions following adverse events. Participants were not asked to give feedback on the findings. Participant feedback could potentially have increased the study's validity because it would have reduced the scope for the researchers' agendas to influence the conclusions (Tong, Sainsbury, \& Craig, 2007). However, it was considered that the researchers' agendas were unlikely to have strong effects on the results obtained because the interviews were compared with clearly defined transformational leadership components (Bass \& Avolio, 1997), and the checklist for interview reporting presented by Tong et al. (2007) was used as a structure for the study report. The interviewer works in the studied organisation as a consultant. There is not a position of supervisory authority over any of the participants. The situation still may have affected the participants' answers.

The interview process could potentially have been improved by making it clear to participants that the discussion about errors and near misses was not intended to deal only with incidents reported using the HaiPro system. Pilot testing could have revealed this issue in advance. As it was, many of the nursing managers focused on feedback-giving and talking about reported incidents during the interviews. Consequently, there may have been too little emphasis on errors that occur without being reported.

Data were collected from managers working in one acute and one primary care hospital. In future, it would be interesting to perform a larger survey to determine how nursing managers perceive their own actions following adverse events from a transformational leadership point of view. It would also be interesting to perform a similar survey of nursing staff to see how their views differ from those of nursing managers.

\section{6 | CONCLUSIONS}

This study has provided new insights into transformational leadership as used by nursing managers in the aftermath of adverse events, showing that managers' actions following such events are partly structured by elements of transformational leadership.

Transformational leadership is important for patient safety, and this work has shown that elements of the transformational leadership style are visible in nursing managers' actions following adverse events. Moreover, the managers generally considered these elements to be important in their work. For example, they recognized a need to ensure that staff regard patients' interests as their top priority. There was general agreement that staff should report errors when they occur, and that nursing managers should give feedback and communicate with 
staff about patient safety incidents without allocating blame and in a way that accounts for any unique aspects of the situation. The nursing managers understand that if they do not seem to care about reports, staff will stop filing reports and it will become more difficult to promote patient safety. Nursing managers must therefore have skills to motivate and empower staff to find new ways of working to prevent adverse events and promote patient safety.

\section{7 | IMPLICATIONS FOR NURSING MANAGEMENT}

Our results show that some elements of transformational leadership are visible in nursing managers' handling of incident reporting, but more is needed. Nursing managers should therefore receive training on patient safety issues, feedback and discussing adverse events. Discussions about adverse events should be conducted in a way that does not cause staff to fear blame or punishment.

Patients' needs are the most important thing in health care, and nursing managers have a duty to develop processes that emphasize their centrality. All decisions should be informed by the patient's point of view. Nursing managers should also be educated about transformational leadership so that they can use it more extensively and effectively in their daily managerial work. The goal of transformational leadership is to transform yourself and your employees simultaneously. This will facilitate the creation of permanent positive changes in patient safety culture, which is a key element in ensuring better patient care.

\section{ACKNOWLEDGEMENTS}

Funding to carry out this study was received from Finnish Nursing Association.

\section{ORCID}

Mari Liukka iD http://orcid.org/0000-0003-1475-1465

\section{REFERENCES}

Agency for Healthcare Research and Quality. (2017, May 26). Root cause analysis. Retrieved from https://psnet.ahrq.gov/primers/primer/10/ root-cause-analysis.

Ammouri, A., Tailakh, A., Muliira, J., Geethakrishnan, R., \& Al Kindi, S. (2015). Patient safety culture among nurses. International Nursing Review, 62(1), 102-110. https://doi.org/10.1111/inr.12159

Bass, B. (1990). From transactional to transformational leadership: learning to share the vision. Organizational Dynamics, 18(3), 19-31. https://doi. org/10.1016/0090-2616(90)90061-S

Bass, B. (1995). Theory of transformational leadership redux. The Leadership Quarterly, 6(4), 463-478. https://doi. org/10.1016/1048-9843(95)90021-7

Bass, B., \& Avolio, B. (1997). Shatter the glass ceiling: women may make better managers in leadership. In K. Grint (Ed.), Leadership: Classical, contemporary, and critical approaches (pp. 199-210). Oxford: Oxford University Press.
Bass, B., \& Steidlmeier, P. (1999). Ethics, character, and authentic transformational leadership behavior. The Leadership Quarterly, 10(2), 181217. https://doi.org/10.1016/S1048-9843(99)00016-8

Cummings, G., MacGregor, T., Davey, M., Lee, H., Wong, C., Lo, E., ... Stafford, E. (2010). Leadership styles and outcome patterns for the nursing workforce and work environment: A systematic review. International Journal of Nursing Studies, 47(3), 363-385. https://doi. org/10.1016/j.ijnurstu.2009.08.006

Doody, O., \& Doody, C. (2012). Transformational leadership in nursing practice. British Journal of Nursing, 21(20), 1212-1218. https://doi. org/10.12968/bjon.2012.21.20.1212

Heuston, M., \& Wolf, G. (2011). Transformational leadership skills of successful nurse managers. Journal of Nursing Administration, 41(6), 248251. https://doi.org/10.1097/NNA.0b013e31821c462

Hillen, H., Pfaff, H., \& Hammer, A. (2015). The association between transformational leadership in German hospitals and the frequency of events reported as perceived by medical directors. Journal of Risk Research, 20(4), 499-515. https://doi.org/10.1080/13669877.2015.1074935

Hoffmann, B., \& Rohe, J. (2010). Patient safety and error management: what causes adverse events and how can they be prevented? Deutsches Arzteblatt International, 107(6), 92-99. https://doi.org/10.3238/ arztebl.2010.0092

Kim, S., \& Yoon, G. (2015). An innovation-driven culture in local government: do senior manager's transformational leadership and the climate for creativity matter? Public Personnel Management, 44(2), 147-168. https://doi.org/10.1177/0091026014568896

Marshall, E. (2011). Expert clinician to transformational leader in a complex healthcare organization. In E. Marshall (Ed.), Transformational leadership in nursing. From expert clinician to influential leader (pp. 1-26). New York: Springer Publishing Company, LLC.

McFadden, K., Stock, G., \& Gowen, C. (2015). Leadership, safety climate, and continuous quality improvement: Impact on process quality and patient safety. Health Care Management Review, 40(1), 24-34. https:// doi.org/10.1097/HMR.0000000000000006

Merrill, K. (2015). Leadership style and patient safety: implications for nurse managers. Journal of Nursing Administration, 45(6), 319-324. https://doi.org/10.1097/NNA.0000000000000207

Munir, F., Nielsen, K., Garde, A., Albertsen, K., \& Carneiro, I. (2012). Mediating the effects of work-life conflict between transformational leadership and health-care workers' job satisfaction and psychological wellbeing. Journal of Nursing Management, 20(4), 512-521. https://doi. org/10.1111/j.1365-2834.2011.01308.x

National Patient Safety Foundation. (2017 April 27). Patient safety dictionary. Retrieved from https://npsf.site-ym.com/?page=dictionaryae

Page, A. (2004). Transformational leadership and evidence-based management. In A. Page (Ed.), Keeping patients safe: Transforming the work environment of nurses (pp. 108-161). USA: National Academies Press.

Qin, C., Xie, J., Jiang, J., Zehn, F., \& Ding, S. (2015). Reporting among nurses and its correlation with hospital safety culture. Journal of Nursing Care Quality, 30(1), 77-83. https://doi.org/10.1097/ ncq. 0000000000000068

Rawat, S. (2015). Impact of transformational leadership over employee morale and motivation. Indian Journal of Science and Technology, 8(S6), https://doi.org/10.17485/ijst/2015/v8iS6/62118

Saeed, T., Almas, S., Anis-ul-Haq, M., \& Niazi, G. (2014). Leadership styles: relationship with conflict management styles. International Journal of Conflict Management, 25(3), 214-225. https://doi.org/10.1108/ IJCMA-12-2012-0091

Tong, A., Sainsbury, P., \& Craig, J. (2007). Consolidated criteria for reporting qualitative research (COREQ): a 32-item checklist for interviews and focus groups. International Journal for Quality in Health Care, 19(6), 349. https://doi.org/10.1093/intqhc/mzm042

Turunen, H., Partanen, P., Kvist, T., Miettinen, M., \& Vehviläinen-Julkunen, K. (2013). Patient safety culture in acute care - a web-based survey of nurse managers' and registered nurses' views in four Finnish hospitals. 
International Journal of Nursing Practice, 19(6), 609-617. https://doi. org/10.1111/ijn.12112

Vaismoradi, M., Griffiths, P., Turunen, H., \& Jordan, S. (2016). Transformational leadership in nursing and medication safety education: a discussion paper. Journal of Nursing Management, 24(7), 970980. https://doi.org/10.1111/jonm.12387

Vaismoradi, M., Turunen, H., \& Bondas, T. (2013). Content analysis and thematic analysis: Implications for conducting a qualitative descriptive study. Nursing \& Health Sciences, 5(3), 398-405. https://doi. org/10.1111/nhs.12048

Vincent, C. (2010). Patient safety. Chichester: Wiley-Blackwell. https://doi. org/10.1002/9781444323856

Vrbnjak, D., Denieffe, S., O'Gorman, C., \& Pajnkihar, M. (2016). Barriers to reporting medication errors and near misses among nurses: a systematic review. International Journal of Nursing Studies, 63, 162-178. https://doi.org/10.1016/j.jnurstu.2016.08.019
Weng, R., Huang, C., Chen, L., \& Chang, L. (2015). Exploring the impact of transformational leadership on nurse innovation behaviour: a cross-sectional study. Journal of Nursing Management, 23(4), 427-439. https://doi.org/10.1111/jonm.12149

Wong, C., Cummings, G., \& Ducharme, L. (2013). The relationship between nursing leadership and patient outcomes: a systematic review update. Journal of Nursing Management, 21(5), 709-724. https://doi. org/10.1111/jonm.12116

How to cite this article: Liukka M, Hupli M, Turunen H. How transformational leadership appears in action with adverse events? A study for Finnish nurse manager. J Nurs Manag. 2018;26:639-646. https://doi.org/10.1111/jonm.12592 